\title{
The interaction between drifting snow and atmospheric turbulence
}

\author{
RighaRd Bintanja \\ Institute for Marine and Atmospheric Research Utrecht, Utrecht University, P.O. Box 80005, 3508 TA Utrecht, The Netherlands
}

\begin{abstract}
This paper presents a modelling study of the influence of suspended snow on turbulence in the atmospheric surface layer. Turbulence is diminished in drifting and blowing snow, since part of the turbulent energy is used to keep the particles in suspension. This decrease in turbulence directly affects the vertical turbulent fluxes of momentum and snow particles (and other scalars), and can effectively be simulated by introducing an appropriate Richardson number to account for the stability effects of the stably stratified air-snow mixture. We use a one-dimensional model of the atmospheric surface layer in which the Reynolds stress and turbulent suspended snow flux are parameterized in terms of their mean vertical gradients (first-order closure). The model calculates steady-state vertical profiles of mean wind speed, suspended snow mass in 16 size classes and stability parameters. Using the model, the influence of snowdrifting on the wind-speed profile is quantified for various values of the initial friction velocity (which determines the steepness of the initial wind-speed profile). It will be demonstrated why the roughness length appears to increase when snowdrifting occurs. Finally, we present a parameterization of the effects of snowdrifting on atmospheric stability which can be used in data analyses as a first-order approximation.
\end{abstract}

\section{INTRODUCTION}

Drifting and blowing snow occur when loose snow particles are available at the surface and when wind speeds increase above a certain threshold value. Then, turbulent motions are able to lift the snow particles upwards against the action of gravity. For moderately strong winds, the particles remain confined very close to the rigid surface and periodically rebound at the surface; this is generally referred to as saltation. For stronger winds, snow particles are able to leave the saltation layer and become suspended. In fully developed blowing snow, saltation and suspension occur simultaneously. In particular, the functional dependence of total snowdrift-transport rates on the wind velocity has been studied widely (e.g. Budd and others, 1966; Radok, 1970; Takeuchi, 1980; Schmidt, 1986; Pomeroy and Male, 1992).

Snowdrifting is one of the many manifestations of twophase flow systems. Therefore, the physical mechanisms involved in the drifting of snow are similar to those investigated in the broad and complex field of two-phase (solidfluid/gas) flows. Analogous processes are, for instance, the drifting of wind-blown desert sand (Bagnold, 1941, 1966), the transport of sediment over the ocean floor and river beds (e.g. Bridge and Dominic, 1984), blood flow, quicksand, sea spray and dense fog.

Snowdrifting occurs regularly over snow-covered regions such as the ice sheets of Antarctica and Greenland. The transport of snow by the wind can be a major massbalance component over snowfields and ice sheets by spatially redistributing the precipitated snow (e.g. Takahashi and others, 1988). Blowing snow over the edge of Antarctica even contributes in an absolute sense to the integrated mass balance. Sublimation of blowing snow also negatively con- tributes to the surface mass balance of snow-covered regions (e.g. Schmidt, 1982; King and others, 1996). Furthermore, the occurrence of snowdrifting causes acceleration of the downslope katabatic winds over sloping surfaces as a result of the increase in near-surface density of the gravity flow (Kodama and others, 1985). Drifting and blowing snow even affect the longwave-radiation balance of the lowest atmospheric layers, as pointed out by Yamanouchi and Kawaguchi (1984). Obviously, the occurrence of drifting snow influences and modifies many physical processes in the near-surface atmospheric layers.

This study focuses on the influence of drifting and blowing snow on the vertical turbulent mixing of momentum and scalars in the atmospheric surface layer. To keep a snow particle in suspension at a certain average height above the surface, the residual upward turbulent stress exerted on the particle must balance the downward force of gravitation. This requires expenditure of the surface-layer turbulence, which is manifested by decreases in turbulence-intensity and turbulent-length scales (Adams and Weatherly, 1981). As the snowdrifting content decreases sharply with height, the surface layer is stably stratified and turbulence is reduced (Wamser and Lykossov, 1995). This mechanism is conceptually similar to a thermally stable turbulent surface layer in which negative buoyancy destroys turbulence (Lumley, 1978). The effect of snowdrifting on turbulence may therefore be described by introducing an appropriate "snowdrift" Richardson number which depends on the vertical turbulent suspended snow flux. Besides showing model results in which this effect is quantified, we will present a simple, first-order parameterization of the stability effects of snowdrifting in terms of known surface-layer variables. As this study is one of the first to discuss the effects of snow- 
drifting on atmospheric turbulence and, since the model that is used includes various assumptions and empirical parameterizations, the results presented here are far from definitive; future work will focus on refining the model.

\section{MODEL DESGRIPTION}

The drifting of snow particles in the air is considered as a two-phase turbulent flow of air mixed with rigid, non-cohesive, inertia-free spherical snow particles, separated sufficiently to be considered isolated so that particle interaction can be safely neglected (Lumley, 1978). Furthermore, it is assumed that volume concentration is high enough so that the air-snow mixture may be regarded as a continuum and that the horizontal velocity of the particles equals that of the air but is low enough to ignore interaction. For this, it is necessary that the particles are small relative to the smallest length scale in turbulence, the Kolmogorov length scale, which is about $1 \mathrm{~mm}$ in the lower atmosphere. This is generally the case for snowdrifting with a particle diameter varying roughly between 40 and $400 \mu \mathrm{m}$ (e.g. Budd, 1966).

\subsection{Saltation of snow}

In our model of the suspension layer, the mass concentration in the saltation layer serves as the lower boundary condition. Snow starts to drift when the friction velocity becomes larger than a certain threshold friction velocity. Assuming that saltation particle velocity is proportional to the threshold friction velocity $u_{*_{\mathrm{t}}}\left(=\sqrt{\tau_{\mathrm{t}} / \rho}\right.$, where $\tau_{\mathrm{t}}$ is the threshold shear stress for snowdrift initiation and $\rho$ is the density of the air-snow mixture) with velocity-proportionality constant $c$, and using the empirically determined relation $c e=0.68 u_{*}{ }^{-1}$ where $e$ is the saltation efficiency and $u_{*}$ is the friction velocity, Pomeroy and Gray (1990) derived the following relation for the saltation-mass concentration $\eta_{\mathrm{s}}\left(\right.$ in $\left.\mathrm{kg} \mathrm{m}^{-3}\right)$ :

$$
\eta_{\mathrm{s}}=\frac{0.68 \rho}{c u_{*} g h_{\mathrm{s}}}\left(u_{*}^{2}-u_{*_{\mathrm{t}}}^{2}\right)
$$

where $g$ is the acceleration of gravity and $h_{\mathrm{s}}$ is the height of the saltation layer. They showed that saltation-mass concentrations evaluated using Equation (1) compared favourably with observed values over a wide range of friction velocities. The height of the saltation layer is assumed to depend on the surface-friction velocity according to measurements made by Pomeroy and Male (1992). They defined $h_{\mathrm{s}}$ as the height where downward-extrapolated suspended-mass concentrations equal the saltation-mass concentration. For various values of the threshold friction velocity, they arrived at the following empirical relation:

$$
h_{\mathrm{s}}=0.0843 u_{*}^{1.27} .
$$

Several authors have argued that the shear stress at the surface remains at the threshold value during snowdrifting, even though the stress applied by the free atmosphere becomes larger (e.g. Bagnold, 1941; Owen, 1964). In order to initiate saltation, the turbulent fluctuations must be able to break the cohesive bonds between the snow crystals at the surface and lift the particle (Schmidt, 1980). According to Pomeroy and Gray (1990), the threshold-friction velocity for fresh, loose, dry snow varies from 0.07 to $0.25 \mathrm{~m} \mathrm{~s}^{-1}$, whereas for old, wind-hardened, dense and wet snow its value can be much larger $\left(0.25-1.0 \mathrm{~m} \mathrm{~s}^{-1}\right)$. In this study, we assume that $u_{*_{t}}$ is independent of particle size.

org/10.3189/1998AoG26-1-167-173 Published online by Cambridge University Press
In order to account for the differences in size and weight of the drifting snow particles, we have subdivided the size spectrum into 16 classes of $30 \mu \mathrm{m}$ width, with particle diameters ranging from 30 to $480 \mu \mathrm{m}$. In the saltation layer, the frequency distribution of particle diameter is prescribed according to the well-known gamma function (with the shape parameter equal to 4 and the mean diameter equal to $200 \mu \mathrm{m}$ (Schmidt (1982)). Budd (1966) and Schmidt (1982) found that the gamma function adequately describes measured particle distributions at various heights in the suspension layer. In the following, we will refer to $\eta_{\mathrm{i}}$ as the mass concentration of particles with radius $r_{\mathrm{i}}$, and to $\bar{\eta}$ as the total mass concentration of suspended snow particles at a specific height above the surface $(z)$ :

$$
\bar{\eta}=\sum_{i=1}^{16} \eta_{\mathrm{i}}
$$

with $\bar{\eta}=\bar{\eta}(z)$. In this study, we will not discuss in detail the simulated particle-size distributions.

\subsection{Suspension of snow}

Snow particles in suspension remain at a certain average height above the solid surface as a result of two balancing forces: the downward force of gravitation and the upward force due to a residual upward turbulent stress (we have neglected possible electrostatic forces). The flow must do work to keep the particles in suspension. Leeder (1983) demonstrated that the upward-directed residual Reynolds stress, arising from asymmetrical shear turbulence, is in balance with the immersed weight of the suspended mass. He found that this upward stress reaches a maximum $30 \%$ of the fluid shear stress $\tau\left(=\tau_{x z}\right)$. There is a net-slip velocity or drag between the fluid and the particles. Hence, the fluid is decelerated and, consequently, turbulence is diminished in the presence of suspended particles (Bridge and Dominic, 1984). Generally, this reduction is due to a reduction in turbulent length scales and to a diminishing of turbulentvelocity fluctuations. If a parcel of the fluid with particlemass concentration equal to the local value changes level by means of turbulent movements, it will experience an anomalous buoyancy (actually a change in drag force exerted on the particles) which forces it back to its original level (Lumley, 1978). This behaviour is conceptually equivalent to that of a thermally stably stratified turbulent surface layer in which real buoyancy effects destroy turbulence. We may therefore describe the influence of a stable suspendedsnow stratification on turbulence in the surface layer by introducing the flux "snowdrift" Richardson number, which is defined as the ratio of destruction of turbulent kinetic energy by buoyancy forces (due to the stable density stratification of the air-snow mixture) and the turbulent energy production by shear (Adams and Weatherly, 1981):

$$
R f_{\eta}=-\frac{g \sigma \overline{\left(\bar{\eta}^{\prime} w^{\prime}\right)}}{\overline{\left(u^{\prime} w^{\prime}\right)} \frac{\partial u}{\partial z}}
$$

where $\overline{\left(\bar{\eta}^{\prime} w^{\prime}\right)}$ is the turbulent flux of suspended snowparticle mass, $\overline{\left(u^{\prime} w^{\prime}\right)}$ is the turbulent-momentum flux, $\sigma\left(=\rho_{\mathrm{s}} / \rho_{\mathrm{a}}-1\right)$ is the relative excess of snow-particle density $\left(\rho_{\mathrm{s}}\right)$ over air density $\left(\rho_{\mathrm{a}}\right)$ and $u$ is the mean horizontal velocity. Note that in the case of snow suspension, the airsnow mixture is always stably stratified, which means that $R f_{\eta}>0$.

In a horizontally homogeneous flow over a flat bottom, 
with the horizontal velocity aligned with the $x$ axis and the $z$ axis positive upward, the governing equations for horizontal velocity and suspended snow-mass concentration in size class i $\left(\eta_{\mathrm{i}}\right)$ are:

$$
\begin{aligned}
\rho \frac{\partial u}{\partial t} & =-\frac{\partial}{\partial z}\left(\rho \overline{u^{\prime} w^{\prime}}\right) \\
\rho \frac{\partial \eta_{\mathrm{i}}}{\partial t} & =-\frac{\partial}{\partial z}\left(\rho \overline{\eta_{\mathrm{i}}^{\prime} w^{\prime}}-\rho V_{\mathrm{i}} \eta_{\mathrm{i}}\right) \quad i=1, \ldots, 16
\end{aligned}
$$

where $\rho \overline{u^{\prime} w^{\prime}}(=-\tau)$ is the Reynolds stress, $\rho=\rho_{\mathrm{a}}(1-C)+$ $\rho_{\mathrm{s}} C$ is the total density (with $C=\bar{\eta} / \rho_{\mathrm{s}}$ is the volume concentration of snow in air) and $V_{\mathrm{i}}$ is the terminal fall velocity of particles with radius $r_{\mathrm{i}}$. The term $-\rho V_{\mathrm{i}} \eta_{\mathrm{i}}$ in Equation (6) represents the downward flux of suspended snow due to the gravity force, in which the particle terminal-fall velocity is taken as

$$
V_{\mathrm{i}}=1.1 \times 10^{7} r_{\mathrm{i}}^{1.8} .
$$

This is an empirically determined relation which takes into account Reynolds number-dependent particle drag (Pomeroy and Male, 1992). In a classical manner, the second-order moments in Equations (5) and (6) are parameterized in terms of the mean gradients (i.e. first-order closure):

$$
\begin{aligned}
-\overline{u^{\prime} w^{\prime}} & =K_{\mathrm{m}} \frac{\partial u}{\partial z} \\
-\overline{\eta_{\mathrm{i}} w^{\prime}} & =K_{\eta} \frac{\partial \eta_{\mathrm{i}}}{\partial z} \quad \mathrm{i}=1, \ldots, 16 .
\end{aligned}
$$

The turbulent-eddy diffusivities of momentum $K_{\mathrm{m}}$ and suspended-snow particles $K_{\eta}$ are written as

$$
\begin{aligned}
K_{\mathrm{m}} & =\frac{\kappa u_{*} z}{\Phi}, \\
K_{\eta} & =\xi K_{\mathrm{m}}
\end{aligned}
$$

in which $\kappa(=0.4)$ is the von Kármán constant, $u_{*}$ is the height-dependent friction velocity and $\Phi$ is the stability function

$$
\Phi=1+A_{\eta} R f_{\eta}
$$

where $A_{\eta}$ is a parameter to be determined empirically. An increase in $\Phi$ (i.e. $\Phi>1$ ) represents a decrease in turbulent intensity under a stable-density stratification, induced by a stable stratification of suspended snow mass $\left(R f_{\eta}>0\right)$. In cases with a stable suspended-sediment gradient, values of $A_{\eta}$ ranging from 5.5 to 7.0 have been reported (Bridge and Dominic, 1984). These values compare well with the "thermal" equivalent of $A_{\eta}$ for a thermally stable surface layer (e.g. Garratt, 1992). Notice that applying the stability concept in terms of the Richardson number provides no information about the nature of the decrease in turbulence (i.e. turbulent length scales or intensity).

The parameter $\xi$ is introduced to allow for a difference in the diffusivity of snow particles compared to the eddy diffusivity of momentum, as was suggested by the results of Sommerfield and Businger (1965). However, in this study we will use $\xi=1$, since we see no a priori reason why the turbulent eddies in the air-snow mixture should affect the momentum and snow fluxes differently. According to Garratt (1992), first-order closure (Equations (8) and (9)) works quite well in stable boundary layers when the transfers are dominated by small eddies of length scales smaller than the typical length scale of the mean gradient, so we may expect that it is applicable here. Finally, notice that Equations (5) and (6) are coupled through the eddy coefficients $K_{\mathrm{m}}$ and $K_{\mathrm{h}}$.

\subsection{Boundary conditions}

As we are interested only in the vertical profiles in the suspension layer, we will have to use saltation-layer variables as a lower boundary condition. We will assume that the suspension-layer characteristics can be extended downward to the so-called focus height $\left(h_{\mathrm{f}}\right)$. This is the height at which the downward-extrapolated wind profiles during snowdrifting appear to intersect each other (Bagnold, 1941; Budd and others, 1966; Shiotani and Arai, 1967; Radok, 1970); hence, it is the height at which the horizontal wind apparently remains constant during snowdrifting. Its presence apparently results from the complex dynamics in the saltation layer which are not very well understood at present. The focus is generally regarded as the height separating the "saltation" regime and the "suspension" regime in fully developed snowdrifting. According to Pomeroy and Gray (1990), the focus height is of the order of $80 \%$ of the mean height of the saltating particle trajectories. Here, we will assume for simplicity that $h_{\mathrm{f}}$ can be regarded invariant under all snowdrifting conditions. (This assumption is not consistent with Equation (2), although Equation (2) is used only to determine the saltation mass concentration; future work will include a flow-dependent focus height.) Since, at the onset of snowdrifting, the logarithmic layer extends downward to the roughness height, the horizontal velocity at the focus height during snowdrifting can be determined from

$$
u\left(h_{\mathrm{f}}\right)=\frac{u_{*_{\mathrm{t}}}}{\kappa} \ln \left(h_{\mathrm{f}} / z_{0 \mathrm{~m}}\right)
$$

where $z_{0 \mathrm{~m}}$ is the intrinsic aerodynamic roughness length for momentum (i.e. the height at which the downward extrapolated wind speed equals zero in the absence of snowdrifting). We will take a value of $z_{0 \mathrm{~m}}$ representative for uniform, flat or slightly undulated snow surfaces, i.e. $z_{0 \mathrm{~m}}=$ $1 \times 10^{-4} \mathrm{~m}$ (e.g. King, 1990; Wieringa, 1993).

The lower boundary condition of the suspended snowmass Equation (6) is given by the relation for the saltationmass concentration (Equation (1)) combined with the particle gamma-distribution function to obtain the saltation-mass concentration for each particle-size class. Note that the saltation-mass concentration can vary during a model run as it depends on an internal model variable (i.e. the friction velocity just above the saltation layer).

The height of the upper boundary $(z=H)$ should be chosen so that (1) surface-layer similarity theory is valid throughout the model domain, and (2) the largest part of the suspended snow mass is below $z=H$. At $z=H$, the turbulent flux of momentum is prescribed according to

$$
\tau_{\mathrm{H}}=\rho u_{* \mathrm{H}}{ }^{2}
$$

where $u_{* \mathrm{H}}$ is the turbulent-velocity scale at $z=H$. In the absence of snowdrifting, application of Equation (5) with the boundary condition (14) yields the common logarithmic wind profile with $u_{*}=u_{* \mathrm{H}}$ at each height.

The upper-boundary condition for snowdrift-particle mass in Equations (6) is that the upward-turbulent diffusion of snow equals the downward flux of snow by gravity in each particle-size class (i.e. zero net mass flux through $z=H$ ).

\subsection{Numerical details and model parameters}

Equations (5) and (6) are solved on a finite-difference grid which is logarithmic in $z$ in order to obtain a relatively high resolution near the surface where the vertical gradients are 
largest. The upper boundary $(H)$ is set to $10 \mathrm{~m}$ with 40 gridpoints evenly spaced in $\ln \left(z / h_{\mathrm{f}}\right)$.

The time differencing is simply forward in time, while the diffusion terms on the right-hand sides of Equations (5) and (6) are solved with central differences. The fluxes of momentum and suspended-particle mass are defined at points midway between the usual gridpoints. The model integrates from an initial wind-speed profile (characterized by different values of $\left.u_{* \mathrm{H}}\right)$ until a steady-state is reached. Table 1 summarizes the values of the various model parameters. With these values, the wind speed at the focus according to Equation (13) equals $3.9 \mathrm{~m} \mathrm{~s}^{-1}$.

\section{Table 1. Values of the model parameters}

\begin{tabular}{ll}
\hline Parameter & Value \\
\hline Focus height $h_{\mathrm{f}}(\mathrm{m})$ & \\
Threshold friction velocity $u_{* \mathrm{t}}\left(\mathrm{m} \mathrm{s}^{-1}\right)$ & 0.05 \\
Ratio of saltation and threshold friction velocities $c$ & 0.25 \\
Ratio of snow and momentum diffusivities $\xi$ & 1.4 \\
Momentum of roughness length $z_{0 \mathrm{~m}}(\mathrm{~m})$ & 1.0 \\
Stability constant $A_{\eta}$ & $1.0 \times 10^{-4}$ \\
& 6.0
\end{tabular}

\section{RESULTS}

We will show the results of experiments with varying initial wind-speed profiles, the steepness of which are determined by the value of $u_{* \mathrm{H}}$. Increasing values of $u_{* \mathrm{H}}$ can be associated with stronger externally forced boundary-layer winds. Figures 1-4 show the vertical profiles of horizontal wind velocity, friction velocity, Richardson number and suspended-mass concentration, respectively, for various values of $u_{* \mathrm{H}}$ such that $u_{* \mathrm{H}}>u_{* 1}$ so that snowdrifting occurs.

In a stable surface layer, the vertical transfer of momentum is initially reduced by the snowdrift-induced diminu-

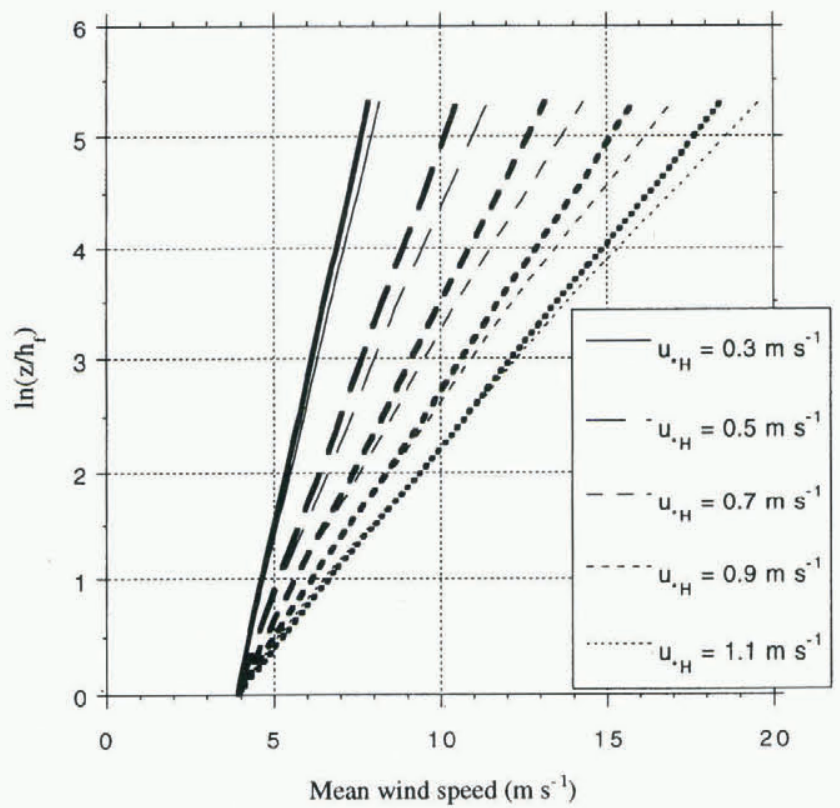

Fig. 1. Steady-state wind-speed profiles (thin lines) for five selected experiments represented by their initial friction velocity $\left(u_{* \mathrm{H}}\right)$. Bold lines represent the usual logarithmic wind-speed profile in the absence of snowdrift. tion of turbulent intensity. This implies that the presence of suspended snow induces a general increase in wind speeds (although near the surface a slight reduction in wind speed occurs), the largest increases occurring at higher levels (Fig. 1). In other words, the mean velocity gradient is larger for the same shear stress when snowdrifting occurs. Obviously, this behaviour is similar to what is commonly observed in thermally stable surface layers (e.g. Garratt, 1992). Figure 2 shows that $u_{*}$ increases upward, which results from the fact that the density of the air-snow mixture decreases strongly with height and that the shear stress $\tau\left(=-\rho \overline{u^{\prime} w^{\prime}}\right)$ must be constant with height in steady-state by virtue of Equation (5). The increase in $u_{*}$ with height becomes stronger when the wind speed is larger and hence more snow can be kept in suspension. Also shown in Figure 2 is $u_{*}{ }^{\prime}$, which is defined as the friction velocity which would be found by an observer unaware of the stability effects induced by snowdrifting. Because of the steeper wind-speed profile in the case of snowdrifting, the observer who assumes a logarithmic wind profile finds a value of $u_{*}{ }^{\prime}$ that is larger than the true friction velocity throughout the surface layer. Obviously, if one neglects the stability effects caused by snowdrifting, the friction velocity would be significantly overestimated.

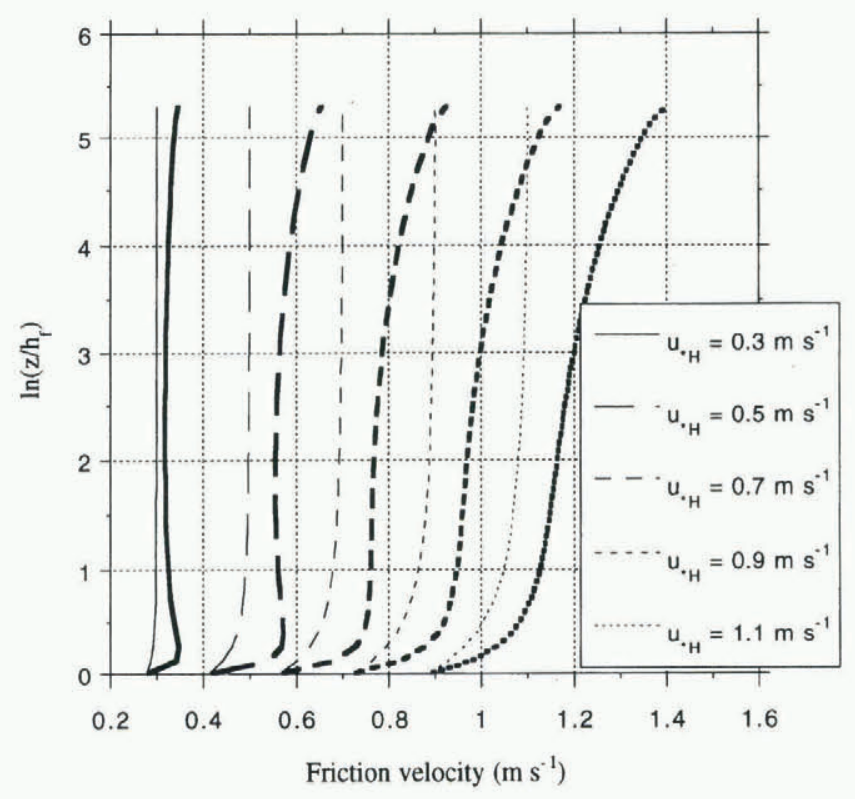

Fig. 2. Vertical profile of simulated steady-state friction velocity (thin lines) for the five selected experiments. Bold lines represent the friction-velocity profiles which would be found if the stability effects of suspended snow are neglected.

The vertical profiles in Richardson number are given in Figure 3. Interestingly, the suspended-snow Richardson number $\left(R f_{\eta}\right)$ takes maximum values close to the surface. This results from the fact that the turbulent snow-particle flux (which is proportional to the snowdrift mass concentration) and the associated buoyancy destruction is maximum near the surface and decreases rapidly upward. The increase in $R f_{\eta}$ at higher levels can be attributed to the usual decrease in turbulent shear production with height (e.g. Garratt, 1992). Interestingly, the Richardson number reaches its maximum value at nearly all heights for intermediate values of the wind-speed gradient $\left(u_{* \mathrm{H}}=0.5\right.$ $\left.0.7 \mathrm{~m} \mathrm{~s}^{-1}\right) . R f_{\eta}$ tends to decrease slightly throughout the surface layer for stronger winds (or, equivalently, for larger 
values of $u_{* \mathrm{H}}$ ). Apparently, the increase in shear production is larger than the increase in snowdrift-induced buoyancy destruction when wind speeds become stronger. This can at least partly be attributed to the fact that the increase in suspended mass with wind speed is largest at low winds by virtue of the dependence of saltation-mass concentration on $u_{*}$ (Equation (4)). The simulated values of $R f_{\eta}$ obtained in these experiments compare favourably with those resulting from the suspended-sediment simulations of Adams and Weatherly (1981). Note, however, that the increase in $R f_{\eta}$ at higher levels depends strongly on the amount of suspended mass. If the simulated drift density at higher levels was smaller, the increase in $R f_{\eta}$ at higher levels would be les pronounced or even absent.

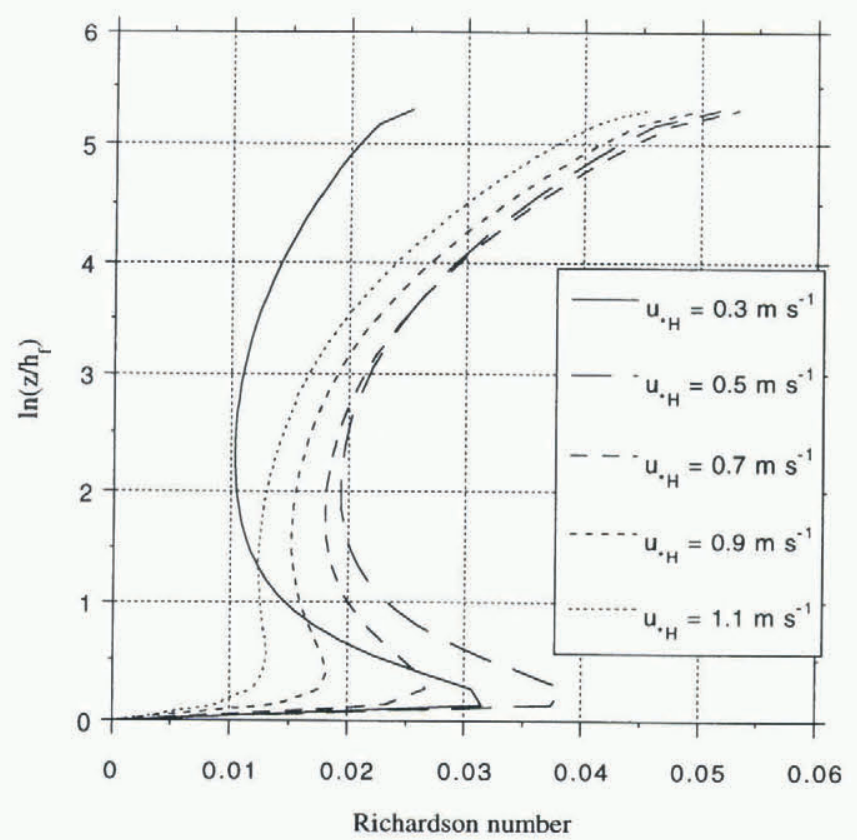

Fig. 3. Vertical profile of the "snowdrift" Richardson number (Equation (4)) for the five selected experiments.

The vertical distribution of suspended mass in the various experiments is shown in Figure 4. The relative increase in suspended mass with $u_{* \mathrm{H}}$ is largest at higher levels, which is due to the fact that both the saltation-mass concentration and the vertical diffusivity of snow increase with wind speed. In all experiments, the suspended-mass concentration decreases by approximately two orders of magnitude with height. This decrease is smaller than that obtained from measurements over a uniform, completely snow-covered plain in Canada in winter (Pomeroy and Male, 1992). This discrepancy may be due to the fact that terminal fall velocities of especially the smallest particles are underestimated by Equation (7) (mean fall velocities range from $1.1 \mathrm{~m} \mathrm{~s}^{-1}$ at the surface to $0.04-0.08 \mathrm{~m} \mathrm{~s}^{-1}$ at $z=H$ ), which leads to an overestimate of the suspended mass of the lightest particles at high levels.

Figure 5 shows the relative change in the turbulent-eddy diffusivity $K_{\mathrm{m}}$ caused by snowdrifting. Clearly, it indicates that when snowdrifting occurs the eddy diffusivity of momentum decreases compared to a similar surface layer without snowdrifting. Although the absolute values of $K_{\mathrm{m}}$ become larger for increasing values of $u_{* \mathrm{H}}$, the largest reduction in $K_{\mathrm{m}}$ relative to the case without snowdrifting occurs for intermediate values of $u_{* \mathrm{H}}$ (by as much as $25 \%$ )
The relatively strong decrease in $K_{\mathrm{m}}$ near the surface results from a diminution of turbulence due to buoyancy as well as from a decrease in friction velocity (see Fig. 2), whereas at higher levels the decrease in $K_{\mathrm{m}}$ is caused exclusively by the increase in Richardson number.

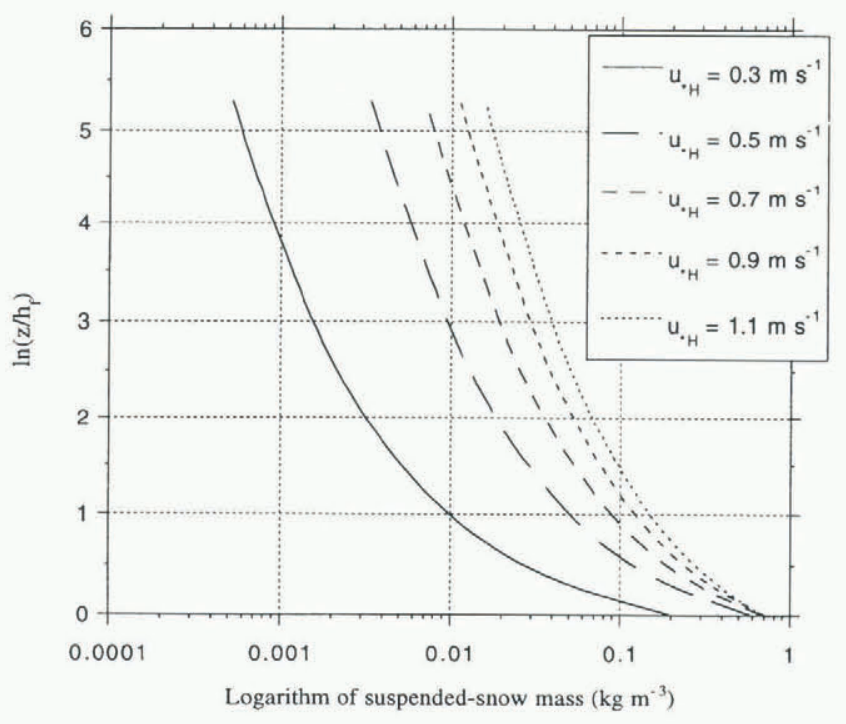

Fig. 4. Vertical profile of the suspended snow mass for the five selected experiments.

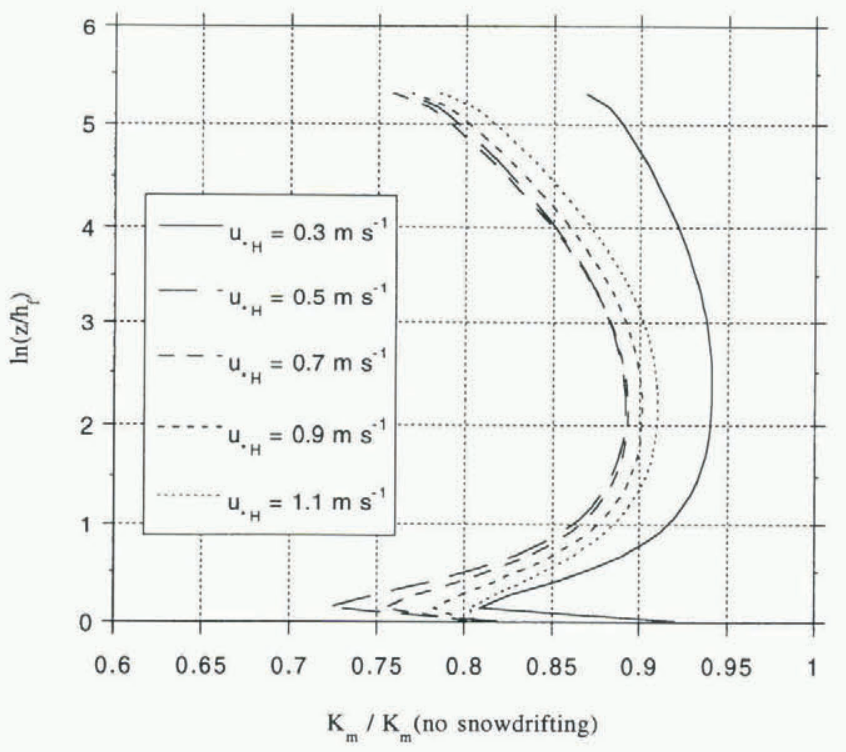

Fig. 5. Vertical profile of the ratio of simulated "snowdrift" eddy diffusivity $\left(K_{\mathrm{m}}\right)$ and the "no snowdrift" eddy diffusivity for the five selected experiments.

Now it is also clear why surface-layer wind measurements indicated that the surface-roughness length appeared to increase with $u_{*}$ in the case of snowdrifting (e.g. Joffre, 1982; Chamberlain, 1983). Not only does the wind-speed profile turn around the focus point (see Fig. 1), the stabilityinduced curvature also increases with increasing $u_{*}$. When roughness lengths are determined from extrapolating downward the wind-speed profile, assuming that the logarithmic wind profile can be extended down to the roughness height (which is not the case since the momentum balance of the saltation layer cannot be described by Equation (5)), both effects contribute to the apparent increase in $z_{0 \mathrm{~m}}$ with $u_{*}$ during snowdrifting. 
Needless to say, the decrease in the vertical turbulent exchange in the surface layer when snowdrifting occurs cannot be neglected in atmospheric models as well as in analysing surface-layer meteorological data. In the next section, we will present a simple parameterization which can be used to quantify the "pseudo"-buoyancy snow effect of suspended snow on the exchange coefficients when snowdrifting physics are not explicitly taken into account or when snowdrifting measurements are not available.

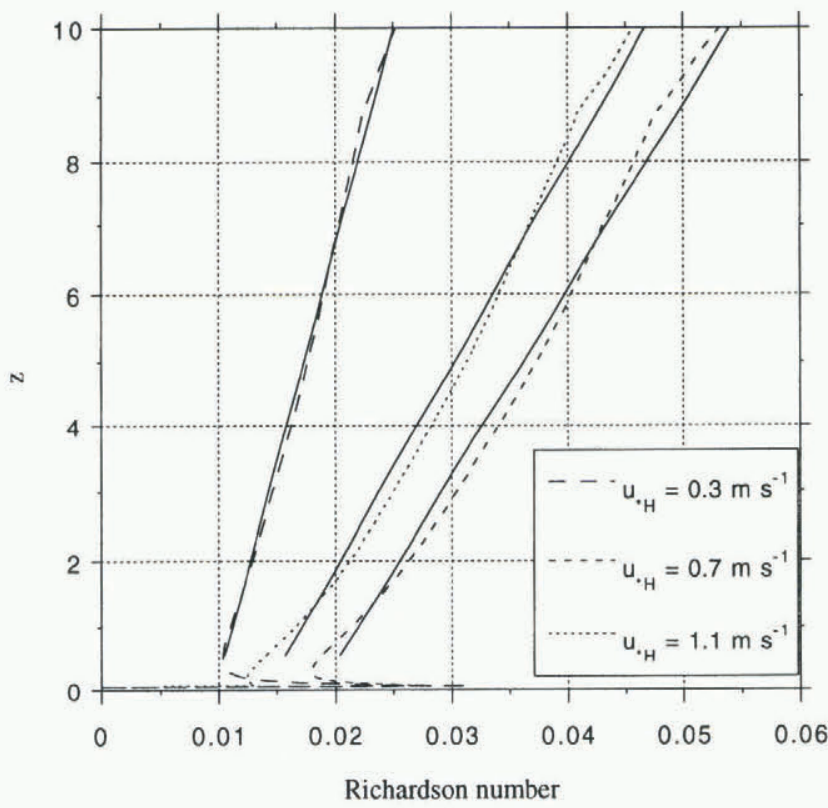

Fig. 6. Variation of Richardson number with height for three selected experiments. The solid lines represent linear fits for $z>0.5 \mathrm{~m}$.

\section{PARAMETERIZATION}

Assuming that $u_{*}$ is independent of height, the vertical wind-speed profile in the suspension layer can be derived analytically from the steady-state Equation (5):

$$
u(z)=\frac{u_{*}}{\kappa}\left[\ln \left(\frac{z}{h_{\mathrm{f}}}\right)+A_{\eta} \int_{h f}^{H} \frac{R f_{\eta}}{z} \mathrm{~d} z\right]+u\left(h_{\mathrm{f}}\right) .
$$

Now consider Figure 6, in which the Richardson number is plotted against height for three selected experiments. Obviously, $R f_{\eta}$ increases roughly linearly with height for $z>$ $0.5 \mathrm{~m}$. Hence, we may approximate the vertical profile in Richardson number according to the linear relation $R f_{\eta}=\alpha+\beta z$, in which the coefficient $\beta$ may be identified with the inverse Obukhov length $L_{\eta}{ }^{-1}$. Equation (15) can then simply be rewritten as follows:

$$
u(z)=\frac{u_{*}}{\kappa}\left[\left(1+A_{\eta} \alpha\right) \ln \left(\frac{z}{h_{\mathrm{f}}}\right)+A_{\eta} \beta\left(z-h_{\mathrm{f}}\right)\right]+u\left(h_{\mathrm{f}}\right) .
$$

The coefficients $\alpha$ and $\beta$ are parameterized in terms of $u_{*}$ by applying linear regressions of the simulated vertical profiles of $R f_{\eta}$ against height for the various experiments (represented by $\left.u_{* \mathrm{H}}\right)$. Figure 7 shows the resulting dependence of $\alpha$ and $\beta$ on $u_{*}$. Clearly, $\alpha$ and $\beta$ reach maximum values in the range of friction velocities considered. This is a manifestation of the fact that the Richardson number takes maximum values for intermediate values of the wind-speed gradient, as explained in the previous section. The coeffiorg/10.3189/1998AoG26-1-167-173 Published online by Cambridge University Press

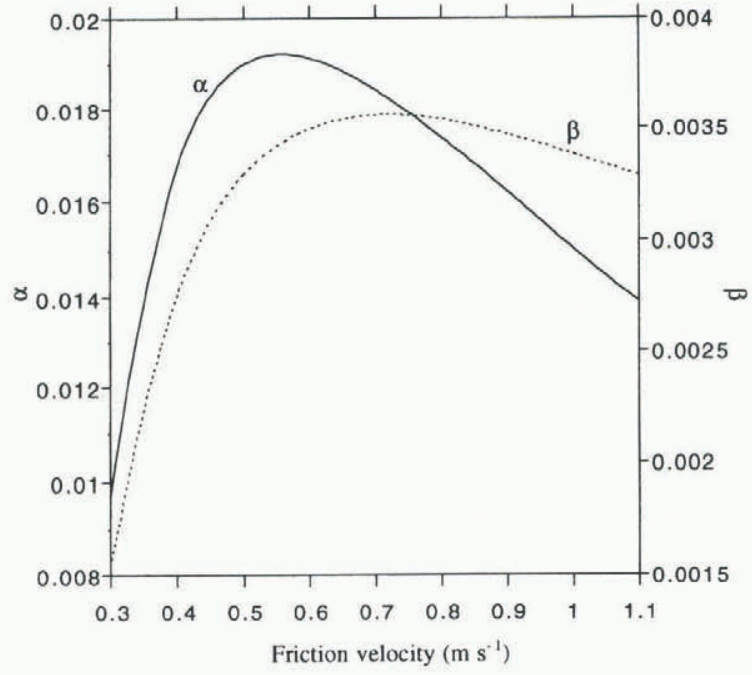

Fig. 7. Dependence of $\alpha$ and $\beta$ on the friction velocity of the initial wind profile. $\alpha$ and $\beta$ are the coefficients of the linear fits of the Richardson number vs height (see Fig. 6).

cients $\alpha$ and $\beta$ are accurately described by the following fourth-order polynomial fits (correlation coefficient $>0.99$ ):

$$
\begin{aligned}
\alpha=- & 0.06295+0.4369 u_{*}-0.8334 u_{*}{ }^{2} \\
& +0.6792 u_{*}{ }^{3}-0.2046 u_{*}{ }^{4}, \\
\beta=- & 0.009277+0.06268 u_{*}-0.1140 u_{*}{ }^{2} \\
+ & 0.09104 u_{*}{ }^{3}-0.02719 u_{*}{ }^{4} .
\end{aligned}
$$

This yields the vertical wind profile relation in Equation (16), which includes the pseudo-buoyancy effects due to snowdrifting, in terms of known surface-layer quantities. The quality of the parameterization can be inferred from Figure 8 , in which the simulated and parameterized windspeed profile are depicted for three values of the initial friction velocity. Clearly, the increase in wind speed due to the occurrence of snowdrifting seems to be parameterized reasonably well. However, the accuracy of the parameterization decreases significantly for large $u_{* \mathrm{H}}$. This is because the decrease in friction velocity near the surface (see Fig. 2), which is largest for high wind speeds, is not taken into account in the parameterization. Hence, the parameterized wind-speed gradient near the surface is overestimated.

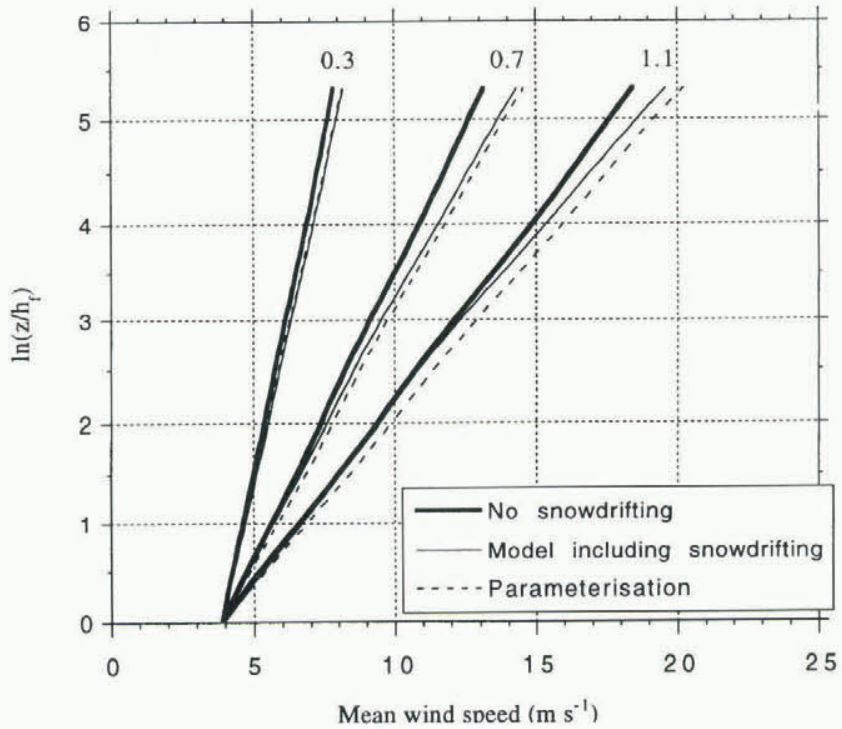

Fig. 8. Comparison of simulated and parameterized vertical wind-speed profiles for three selected cases. The numbers represent the values of $u_{* \mathrm{H}}\left(\mathrm{ms}^{-1}\right)$ in each case. 
If the eddy diffusivities of scalars (e.g. potential temperature and specific humidity) are assumed to be identical to $K_{\mathrm{m}}$, the parameterization may also be used to quantify the snowdrift effect on the vertical scalar profiles. This parameterization provides a simple way to take into account the buoyancy effects due to a stable snowdrift-density profile if no quantitative information about snowdrifting is available. However, one must bear in mind that the model was not tested for different values of the various model parameters (e.g. $u_{*_{1}}$ ). Therefore, the parameterization presented here should be regarded as giving only a first-order estimate of the effect of suspended snow on the turbulent exchange coefficients in the atmospheric surface layer. In future studies, a more accurate parameterization will be constructed.

\section{DISGUSSION AND CONCLUSIONS}

In this study, we have described a model of the atmospheric surface layer that includes snowdrifting. The model calculates the vertical profiles of wind speed and suspended-snow mass in 16 size classes using first-order closure of the turbulent fluxes of momentum and suspended snow. Turbulence decreases to keep the suspended-snow particles at a certain average height against the action of gravity; hence the turbulent energy available for the vertical turbulent transport of momentum and suspended snow is reduced. Consequently, the eddy diffusivities decrease if snowdrifting occurs, causing larger vertical gradients to be necessary to maintain the same turbulent fluxes (Lumley, 1978). The "pseudo"-buoyancy destruction in the case of a stably stratified air-snow mixture is conceptually equivalent to that of a thermally stable atmosphere and can therefore be described in terms of the appropriate Richardson number.

The model results clearly demonstrate the importance of snowdrifting on the vertical wind-speed profile. As a result of the stable stratification of suspended snow, the wind speeds increase throughout most of the atmospheric surface layer, especially at the highest levels. The eddy diffusivity decreases (by $10-25 \%$ ) compared to a similar case without snowdrifting. The associated Richardson number $\left(R f_{\eta}\right)$ takes large values close to the focus since the turbulent suspended-snow flux is largest close to the saltation-suspension interface. $R f_{\eta}$ decreases sharply to about $0.5 \mathrm{~m}$, above which it increases roughly linearly with height. Note that increases in $R f_{\eta}$ with height may be overestimated in this study, as the decrease in suspended-snow concentration with height is underestimated by the model. The steady-state momentum-budget equation canbe solved analytically if $R f_{\eta}$ is assumed to depend linearly on height, yielding a log-linear wind-speed profile. The coefficients of the linear relation between $R f_{\eta}$ and height are parameterized in terms of friction velocity by calculating the model steady-state solution for various initial wind-speed profiles. This leaves an explicit log-linear vertical wind-speed profile in terms of known surface-layerquantities. It is demonstrated that the parameterized wind-speed profiles resemble fairly well the simulated ones. This simple parameterization gives a first-order estimate of the effects of snowdrifting on the vertical profiles of wind (and also scalars) and can be used when detailed information about snowdrifting quantities are lacking. One should bear in mind that the results of this study rely to some extent on a number of assumptions and empirical parameterizations. However, we are convinced that these do not influence our results in a qualitative sense.

\section{ACKNOWLEDGEMENTS}

The author expresses his thanks to the members of the Ice and Climate Group of the Institute for Marine and Atmospheric Research Utrecht for their comments on an earlier version of this paper. Financial support was provided by The Netherlands Antarctic Research Programme (GOA).

\section{REFERENCES}

Adams, C. E., Jr and G. L. Weatherly. 1981. Some effects of suspended sediment stratification on an oceanic bottom boundary layer. 7 . Geophys. Res., 86 (C5), 4161-4172.

Bagnold, R. A. 1941. The physics of blowing sand and desert dunes. London, Methuen.

Bagnold, R. A. 1966. An approach to the sediment transport problem for general physics. U.S. Geol. Surv. Prof. Pap. 422-I.

Bridge, J. S. and D. F. Dominic, 1984. Bed load grain velocities and sediment transport rates. Water Resour. Res., $20(4), 476-490$.

Budd, W. F. 1966. The drifting on non-uniform snow particles. In Rubin, M. J., ed. Studies in Antarctic meteorolog). Washington, DC, American Geophysical Union, 59-70. (Antarctic Research Series 9.)

Budd, W. F., R. J. Dingle and U. Radok. 1966. The Byrd Snow Drift Project: outline and basic results. In Rubin, M. J., ed. Studies in Antarctic meteorology. Washington, DC, American Geophysical Union, 71-134. (Antarctic Research Series 9.)

Chamberlain, A. C. 1983. Roughness length of sea, sand and snow. Boundary-Layer Meteorol., 25 (4), 405-409.

Garratt, J. R. 1992. The atmospheric boundary layer. Cambridge, Cambridge University Press.

Joffre, S. M. 1982. Momentum and heat transfers in the surface layer over a frozen sea. Boundary-Layer Meteorol., 24 (2), 211-229.

King, J. C. 1990. Some measurements of turbulence over an Antarctic ice shelf. Q. J. R. Meteorol. Soc., 116, 379-400.

King, J. C., P. S. Anderson, M. C. Smith and S. D. Mobbs. 1996. The surface energy and mass balance at Halley, Antarctica during winter. 7 . Geophys. Res., 101(DI4), 19,119-19,128.

Kodama, Y., G. Wendler and J. Gosink. 1985. The effect of blowing snow on katabatic winds in Antarctica. Ann. Glaciol., 6, 59-62.

Leeder, M. R. 1983. On the dynamics of sediment suspension by residual Reynolds stresses - confirmation of Bagnold's theory. Sedimentology, 30, $485-491$.

Lumley, J. L. 1978. Two-phase and non-Newtonian flows. In Bradshaw, P., ed. Topics in applied physics. Vol. 12. New York, Springer, 289-324.

Owen, P. R. 1964. Saltation of uniform grains in air. 7. Fluid Mech., 20 (2), $225-242$.

Pomeroy, J.W. and D. M. Gray. 1990. Saltation of snow. Water Resour. Res., 26 (7), 1583-1594

Pomeroy, J.W. and D. H. Male. 1992. Steady-state suspension of snow. f. Hydrol., 136 (1-4), 275-301.

Radok, U. 1970. Boundary processes of drifting snow. In Studies on drifting snow. Melbourne, University of Melbourne. Meteorology Department. (Meteorology Report 13.)

Schmidt, R. A. 1980. Threshold wind-speeds and elastic impact in snow transport. f. Glaciol., 26 (94), 453-467.

Schmidt, R. A. 1982. Vertical profiles of wind speed, snow concentration and humidity in blowing snow. Boundary-Layer Meteorol., 23 2), 223-246.

Schmidt, R. A. 1986. Transport rate of drifting snow and the mean wind speed profile. Boundary-Layer Meteorol., 34(3), 213-241.

Shiotani, M. and H. Arai. 1967. On the vertical distribution of blowing snow. In Ōura, H., ed. Physies of snow and ice. Vol. I, Part 2. Sapporo, Hokkaido University: Institute of Low Temperature Science, 107.5-1083.

Sommerfeld, R. and J. N. Businger. 1965. The density profile of blown snow. 7. Geophys. Res., 70 (14), 3303-3306.

Takahashi, S., R. Naruse, M. Nakawo and S. Mae. 1988. A bare ice field in east Queen Maud Land, Antarctica, caused by horizontal divergence of drifting snow. Ann. Glaciol., 11, 156-160.

Takeuchi, M. 1980. Vertical profile and horizontal increase of drift-snow transport. J. Glaciol., 26 (94), 481-492.

Wamser, C. and V. N. Lykossov. 1995. On the friction velocity during blowing snow. Contrib Atmos. Phys., 68 (1), $85-94$.

Wieringa, J. 1993. Representative roughness parameters for homogeneous terrain. Boundary-Layer Meteorol., 63, 323-363.

Yamanouchi, T. and S. Kawaguchi. 1984. Longwave radiation balance under a strong surface inversion in the katabatic wind zone, Antarctica. 7 . Geophys. Res., 89(D7), 11,771-11,778. 